Article

\title{
The Status Quo of the Criminal Accountability for Marine Illegal Fishing in China: From the Perspective of Judgment Analysis
}

\author{
Li Feng ${ }^{1}$, Peipei He ${ }^{1, *}$, Chenghui Zheng ${ }^{2}$ and Pei Chen ${ }^{1}$ \\ 1 Faculty of Law, Fuzhou University, Fuzhou 350117, China; sherry_feng@126.com (L.F.); \\ Chenpei1001@126.com (P.C.) \\ 2 Fujian Provincial Academy of Environmental Science, Fuzhou 350003, China; lylzzch@163.com \\ * Correspondence: hpp@fzu.edu.cn
}

Received: 27 August 2020; Accepted: 29 September 2020; Published: 10 October 2020

\begin{abstract}
Over the past few years, China's marine economy has been vigorously booming, while strong measures have been equally undertaken to ensure superior quality of the marine environment. However, the country is still suffering illegal fishing problems, which hinder the marine ecological environment and fishery resources from reaching sustainable development both internally and globally. To this end, the Chinese government has ratified a series of legal documents to provide the basis for judicial departments to hold individuals and groups responsible for practicing illegal fishing at sea. Although the measures have indeed performed well in some instances, a number of legal obstacles remain to be fixed. In this article, to realize the status quo of the control of maritime illegal fishing in China, all the criminal judgments relevant to illegal fishing at sea from 2014 were collected and analyzed not only qualitatively but also quantitatively, through which the existing problems of accountability for illegal fishing at sea in China were summarized. In addition, a number of related studies were examined and in-depth interviews were organized to clarify the main reasons for these problems and propose some necessary solutions. It is believed that our findings would not only help to improve the control of maritime illegal fishing and boost the marine ecological environment protection in China, but also to establish a possible reference for other countries in the world.
\end{abstract}

Keywords: marine illegal fishing; criminal accountability; criminal judgments

\section{Introduction}

Illegal fishing has been deemed as a major burden imposed on the global marine ecosystem and environmental protection which is also threatening marine biodiversity, as described in the Millennium Development Goals (MDGS) reports (Fu et al. 2014). Over the past two decades, there has been a remarkable depletion of fishery resources caused by excessive illegal fishing, and some marine species are even on the brink of extinction. As a result, many countries have adopted a range of measures to curtail such a devastating practice.

Typically, the "European Union's Regulations on Combating Illegal Fishing" consists of a set of rules and regulations (Council Regulation (EC) No. 1005/2008 and Council Regulation (EC) No. 1224/2009) ratified by all the European Union members. As expected, these regulations do elucidate the relevant penalties for the people and agencies using illegal vessels, laying the legal basis for the fight against illegal finishing to all the European Union members (Wang 2018). Other countries (e.g., the United States and Australia) have equally adopted stringent legal measures. In the USA, for example, President Obama signed into law H.R.774 in 2015, the "Illegal, Unreported, and Unregulated Fishing Enforcement Act", which aims at the control of the entry of the illegally fished aquatic products 
into American ports and markets, thereby strictly banning their marketing and commercialization (Wang et al. 2017). Likewise, Australia has echoed these measures in countries around the world and further introduced its own rigorous legal measures to curtail illegal fishing activities. Among them, "The 1991 Fisheries Management Act" is the most dramatic legal document, which stipulates that all the fishing actions should get permission from the local government in advance. Meanwhile, any fishing vessel should be registered with the monitoring system (VMS) and be supervised by the system time to time to make sure their fishing action is legal. This process's management cost is relatively low, and it achieves remarkable results (Le Gallic and Cox 2006). However, although many countries have taken relevant measures to curtail and stop illegal fishing, this illegal practice still remains and there is still a long way to go.

China is considered one of the largest maritime countries in the world, exhibiting a ocean area of 2.997 million square kilometers. About one-third of the country's land area is covered by water, and there exists a wide variety of marine fishery resources. Its marine aquatic products alone take up over $50 \%$ of the country's aquatic products production (Yue and Wang 2017). However, since the end of the last century, as impacted by overfishing and marine pollution, the marine ecosystems have been severely damaged, and the fishery resources have been severely reduced. This serious situation has attracted the attention of the Chinese government. Accordingly, a series of measures and regulations have been adopted.

In terms of legislation, amendments to the "Environmental Protection Law" and "Marine Ecological Environment Protection Law" were signed to control illegal fishing and further to facilitate the environmental protection. To make sure the law is enforced effectively and efficiently, the China Maritime Police Bureau has been built up to uniformly exercise its maritime power and law enforcement duties from 1 July 2018. Meanwhile, several maritime police workstations in different regions of the country have been set up to solve the problem of the legal enforcement power insufficient and decentralization (Wang and Chen 2014). In terms of justice, the different judicial organs have enhanced their co-efforts to punish illegal fishing and environmental pollution crimes (Long 2013). To date, the phenomenon of fishing at sea during the ban period and in the prohibited fishing areas continues to occur from time to time in China.

In view of this, in this article, some works are done: Firstly, all the criminal judgments released by the judicial system pertinent to illegal fishing in China are collected and analyzed to summarize the key problems. Secondly, the main reasons for these problems are clarified through the interviews and cross-examination with the information available in the existing literature. Lastly, suggestions are proposed in a targeted manner based on our findings and collected. Although the proposed solutions are solely consistent with the findings and the bibliography of this study alone, it is believed that the evidence and findings documented in this study present critical insights, which can help the government agencies and policymakers in their efforts to fight against illegal fishing and protect the marine ecological environment.

\section{Material and Methodology}

To draw reasonable conclusions and offer practical solutions, the criminal judgment documents relevant to illegal fishing at sea were collected analyzed not only qualitatively but also quantitatively, through which the current status and existing problems of accountability for illegal fishing at sea in China were summarized. In addition, in-depth interviews were organized, and the emphasis was placed on the most critical issues. Meanwhile, a number of reasonable solutions are proposed.

\subsection{Selection of Samples/Interviewees}

To put this into perspective, it is important to first explain what the court verdict is. Court verdict refers to the legally effective judicial document provided by the People's Court after the court exercises its judicial power on behalf of the state. Court verdict truthfully records the process and the results of the trial and clearly reflects every parties' (e.g., the judges, administrative officers, prosecutors, defendants, 
and victims) understanding of the case and attitudes during the law enforcement proceedings. According to the "People's Court's Provisions on the Publication of Judgment Documents on the Internet" rendered by the Chinese Supreme People's Court in January 2014, all judgment documents of the People's Courts should be made available to the public through an official online platform (http://wenshu.court.gov.cn/), making it convenient for interested people to be able to collect all the criminal judgment documents relevant to illegal fishing at sea from 2014, which are evidently the most comprehensive and authoritative sources for this subject study.

Currently, the above-mentioned official website contains the largest number of court verdicts/documents in China. As of 31 October 2018, about 55.13 million court verdicts had been announced, and the overall number of visits had reached 20.014 billion (Hao 2019). The term "illegal fishing at sea" was adopted as the keyword for the full-text search on the aforementioned website, and all the related court verdicts from 2014 to 2019 were collected (i.e., 611 in total). Subsequently, in-depth interviews were organized with people with firsthand information, which further helped us to gain additional insights into certain social phenomena, discuss their forming process, and envisage relevant solutions for identical social problems (Sun 2012). To better summarize valuable reasons and provide meaningful suggestions, both face-to-face and telephone interviews were carried out with 47 highly experienced administrative officers, court judges, prosecutors, and relevant scholars having personally handled cases related to illegal fishing at sea. Given the interviewees' requirements, their conversation content was not disclosed in the article, and only statistics on the conversation content were reported. In the first step of the interview, the research group elucidated the case data of the previous survey to the interviewees to ensure that they understood the content and purpose of our survey. During the course of the interview, we asked the interviewees to help us summarize the reasons for the problems and propose some suggestions for improvement based on their own experience.

\subsection{Processing of Samples Data}

To better reflect the current status and problems of accountability regarding illegal fishing at sea in China, a qualitative and quantitative analysis of the case materials was conducted as follows. First, a statistical analysis of the annual number and distribution of cases in the country was conducted to gain insights into the current intensity and frequency of accountability for illegal fishing in China. Second, details of the different cases were summarized and organized in different categories based on their level of similarity. Third, a statistical analysis of the results of the court verdicts was conducted, and the trials of the cases in various regions were comparatively analyzed. Finally, both the evidence chain and the trial logic of the courts were analyzed. Aiming at the interview records, the interviewees' responses were organized and analyzed, then the contents were summarized outlining the different problems reported by the interviewees and their subsequent suggestions for lasting improvement.

\section{Results and Analysis}

In 2014, the 4th plenary session of the 18th central committee of the Communist Party (Chen 2015) sought to establish the core status of the trial in criminal proceedings. It was indicated that the detection, prosecution, and execution should be conducted consistent with the requirements and standards of court trials as well as the judgments on fact-finding and application of the law. As previously indicated, the present study analyzes the current situation of criminal accountability and the judicial judgments in China vis-à-vis illegal fishing at sea. Consistent with the information provided in Section 2 of this study, all judgments reviewed are available on the China Judgment Documents Network (http://wenshu.court.gov.cn/) which is an official website dedicated to this purpose. Our study's time frame was limited to a 6 year period, and only data from 1 January 2014 to 31 December 2019 (hereinafter referred to as the "investigation period") were considered. After all these judgments were examined, a number of problems were uncovered, some of which will be elucidated in the remaining part of this section of the study. 


\subsection{Insufficient Number of Accountable Cases}

Information obtained from the "China Judgment Documents Network" indicates that a total of 611 criminal judgments pertinent to illegal fishing at sea during the entire investigation period were recorded. Among all the aforementioned criminal judgments, 25 cases were conducted in 2014, 64 in 2015, 82 in 2016, 135 in 2017, 158 in 2018, and 147 in 2019. It is suggested that the number of cases increased year by year in general (Figure 1), reflecting the strengthening of the Chinese government's policies and measures in place to limit illegal fishing at sea.

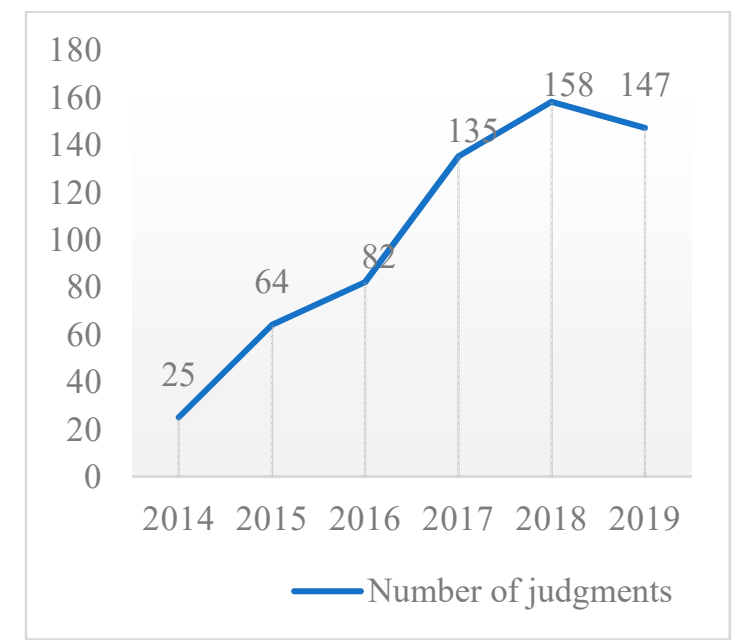

(a)

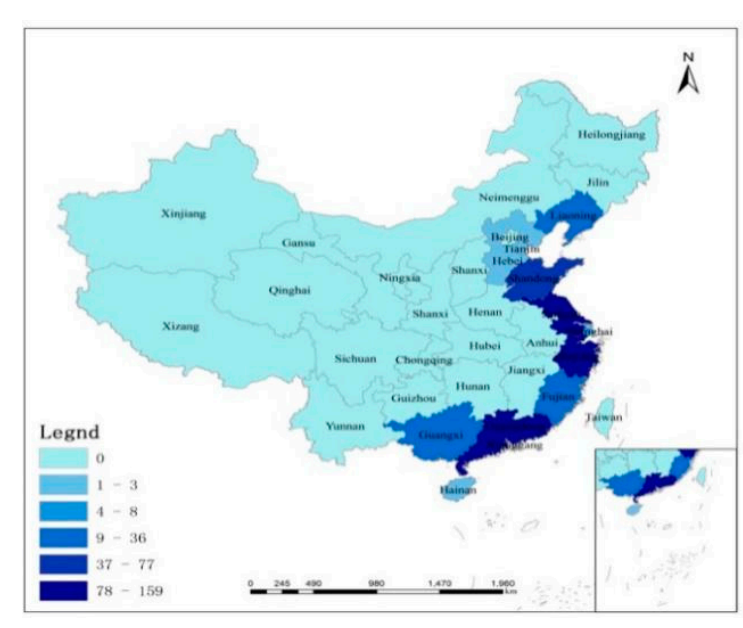

(b)

Figure 1. (a) Statistical analysis on the number of the criminal cases of illegal fishing from 2014 to 2019 in China; (b) statistical analysis of the geographic distribution of the criminal cases of illegal fishing from 2014 to 2019 in China.

Obviously, the number and the geographic distribution of the cases outlined in Figure 1 above do not match to the real situation of the marine resources in China. It is known that the total length of the Chinese coastline is nearly $32,000 \mathrm{~km}$, covering $18,000 \mathrm{~km}$ of the mainland's coastline and 14,000 km of the islands' coastline. Of significance, compared with other environmental crimes, the level of accountability of crimes involving illegal fishing at sea is relatively low. Looking at the information provided on the identical website, during the same investigation period, there were 38,944 judgment documents of the crimes related to illegal felling of forests, which is 62 times the number of crimes relating to illegal fishing at sea. Similarly, there were 6236 verdicts of crimes related to illegal mining (i.e., 10 times the number of crimes relating to illegal fishing at sea), 1893 verdicts on the crime of illegal hunting (i.e., 3 times the number of crimes relating to illegal fishing at sea). In a similar fashion, there is a significantly clear gap between the level of accountability in crimes committed at sea as related to illegal fishing (611) and those committed on inland waters (7321) during the same investigation period (see Figure 2). 


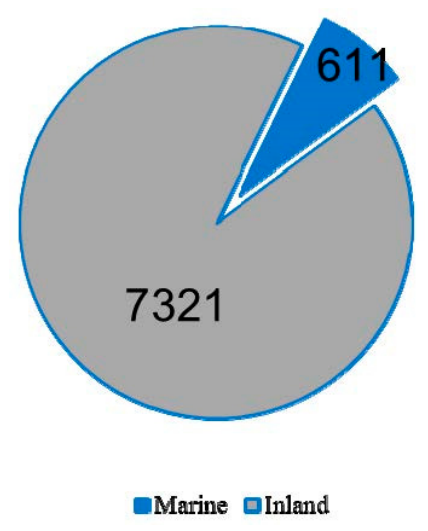

Figure 2. Comparison between the number of "inland waters" and "maritime" illegal fishing cases.

\subsection{Limited Type of Accountability Cases}

A comparison between the judgments indicates that most of the details in different cases are similar, that the offenders either used prohibited tools or went fishing in the closed period and/or restricted area. Among all the collected verdicts, $94.2 \%$ of the cases were individual crimes, and most of the defendants were illiterate. However, considerable evidence suggests that the bigger threats to marine biodiversity, marine environment, and fishery resources were commonly posed by group crimes (Xinhua News 2019). These types of crimes were always well organized, and the offenders often used high-tech and sophisticated fishing facilities. However, only a few cases pertinent to group crimes were found in the collected cases here, suggesting that additional measures and law enforcement strategies are highly warranted to effectively curtail and stop this malicious activity.

\subsection{Large Regional Differences in Accountability}

There are 11 coastal provinces in China not considering Taiwan, Hong Kong, and Macao. Therefore, our statistical analysis revealed that the cases pertaining to illegal fishing at sea can only be inquired from these 11 provinces. Among all the cases investigated, we found that 146 cases were in Zhejiang Province (taking up to $23.9 \%$ of the total number of cases), 159 cases were in Guangdong Province (taking up 26.02\% of all), 139 cases were in Jiangsu (taking up 22.75\% in total); regarding the remaining four provinces and cities (Hebei, Hainan, Shanghai, and Tianjin), each of them only had single-digit cases. A statistical representation of these cases is reported in Figure 3.

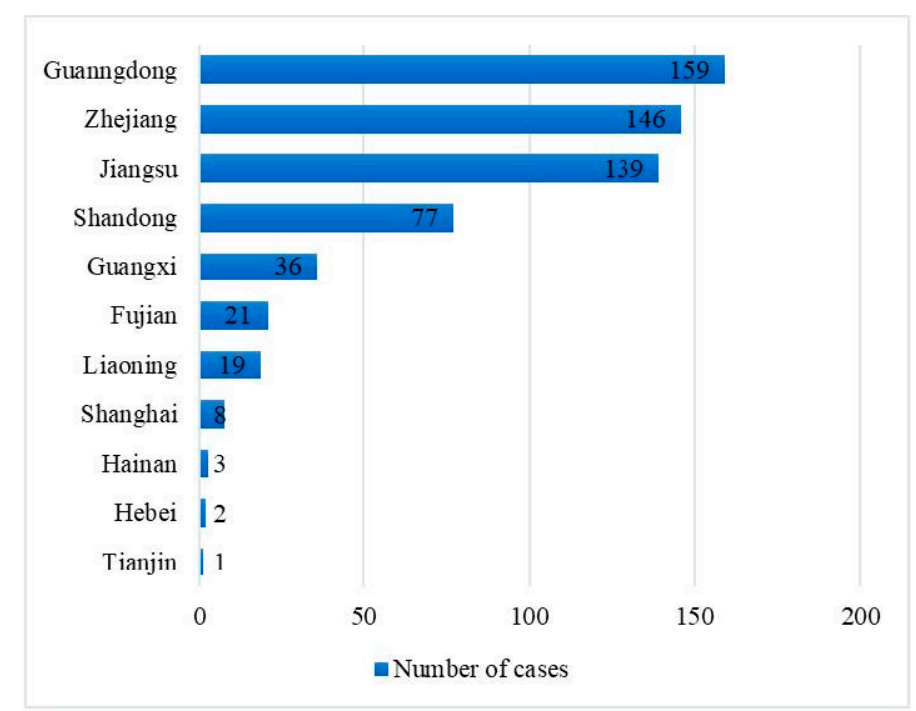

Figure 3. Illustration of the number of cases of "illegal fishing at sea" in different regions of the country. 
The aforementioned data reflect China's level of criminal accountability of illegal fishing at sea. Consistent with the information provided, it is clear that different regions have consistently assigned different efforts to fight against illegal fishing at sea, which further reaffirms our findings that a significant difference exists in the regional accountability.

\subsection{Insufficient Criminal Penalties}

According to Article 340 of "The Criminal Law of the People's Republic of China" (hereinafter referred to as "Criminal Law"), whoever is in violation of the law or regulations on the protection of aquatic resources, or catches any aquatic products in an area or during a season closed to fishing or uses prohibited fishing tools or methods on purpose, if the circumstances are serious, shall be sentenced to fixed-term imprisonment for not more than three years, criminal detention or public surveillance or be fined. The present study uncovered that 1086 offenders were involved in the 611 cases counted. To be specific, 778 of them received the penalty of restricting personal freedom (taking up $71.64 \%$ of the total number), among which 327 were sentenced to fixed-term imprisonment, 444 were sentenced to criminal detention, and 12 were sentenced to public surveillance. Meanwhile, 308 of the offenders were ordered to pay fines, comprising $28.36 \%$ of the total number of individuals sentenced (see Figure 4).

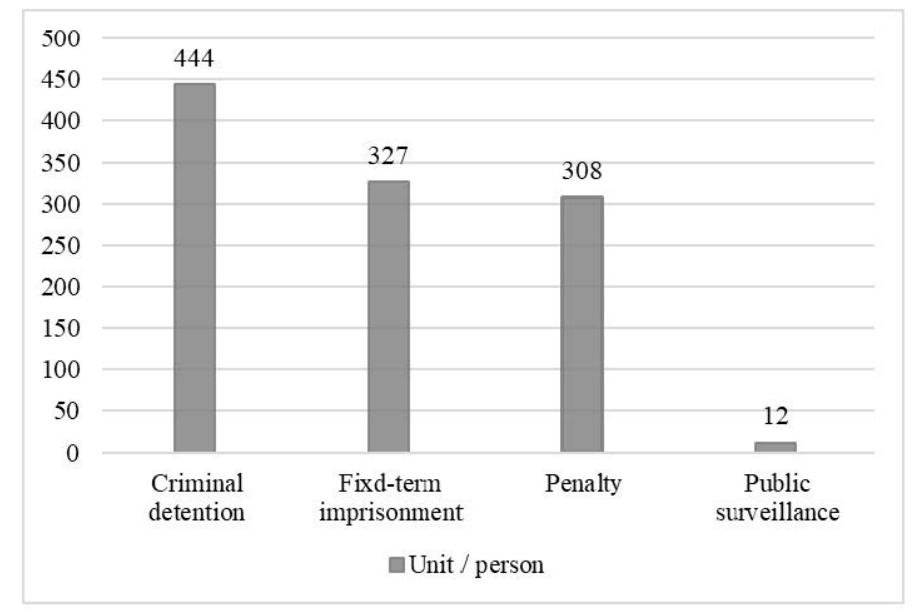

Figure 4. The statistical report of the sentences pertinent to illegal fishing at sea in China.

In general, the type and the strength of the sentence for the offenders are usually based on the occurrence and severity of the crimes committed. By analyzing and comparing all the judgments we found that the fines always range from 2000 to 20,000 RMB, fixed-term imprisonment generally ranges from 6 to 12 months; public surveillance is generally between 4 and 9 months; and criminal detention is generally between 2 and 4 months. In general, the period of restricting the person's freedom rarely exceeds one year, and for which the court tends to adopt probation measures. It was found that probation was adopted in 409 cases, comprising $66.93 \%$ of all cases analyzed in this study. Given the above-reported data, it could be concluded that the current criminal penalties for marine illegal fishing in China are not handled strictly.

\subsection{Large Distinctions of Sentencing in Different Regions}

According to the judgment documents collected by our research group for the present study, it was found that the sentencing schemes adopted by the different regional courts are noticeably different for similar cases. For instance, we found two similar cases, namely, People's Procuratorate of Zhaoyuan City v. Xu Moujia, Xu Mouyi (No. 258) in Shandong Province, as well as People's Procuratorate of Xiangshan City v. Chen Haibin, Zhang Genmu (No. 714) in Zhejiang Province. In these two analogous cases, both of the defendants used illegal fishing tools during the fishing ban period to catch the nearly the same amount of fishes, but the courts' final decisions were different. The court in Shandong 
Province sentenced the defendant to a fine of just 5000 RMB, while the court in Zhejiang Province sentenced the defendant to 6 months of imprisonment. To a certain extent, this reflects the lack of uniform sentencing standards and guidelines in the country's efforts to curtail illegal fishing at sea, as well as the status of different verdicts rendered for the identical cases.

\subsection{Inconsistent Evidence Chain}

According to Article 340 of the Criminal Law, the key point to the conviction of the crimes of illegal fishing is to demonstrate that the criminal suspect catches aquatic products in an area or during a season closed to fishing, or uses prohibited fishing gear or methods for the purpose, and these kinds of circumstances are serious. However, there are currently no unified and specific standards to explain the exact meaning of some core words, such as "the fish prohibition period", "the area closed to fishing", "the circumstances are serious", etc. Therefore, the proving criteria for these key points are quite different in current judicial practice. Some courts have identified what is known as the "fish prohibition zone" arbitrarily according to the administrative agencies' judgment, e.g., in the case of Cangnan County People's Procuratorate v. Chen Qingren (No. 756). In other cases, the court tended to make judgments based on pieces of evidence that are more sufficient and objective. For instance, in the case of Jinjiang People's Procuratorate v. Chen Jianzhu (No. 493), the following evidence was used to judge if the offence spot located in the "fish prohibition zone": (a) AIS route maps, (b) bottom trawl no-fishing area connection map, (c) administrative investigation reports and (d) schematic diagram outlining the boundaries of illegal fishing areas defined by the provincial government. Consistent with the aforementioned, it is clear that the evidence chain of the court's conviction on the crime of illegal fishing aquatic products is unclear and exhibits considerable differences.

\subsection{Insufficient Case Transfer by the Administrative Departments}

After analyzing the different judgments and some relevant documents, it was clearly revealed that almost all the cases of illegal fishing at sea were always investigated by the administrative departments, and in some of them, the suspects were also even punished by administrative departments. However, there were only 220 of the abovementioned cases originated from the active and direct transfer from these administrative departments, comprising only $36 \%$ of all cases presented to the courts. This further indicates that considerable cases involving illegal fishing crimes have not been transferred. It is fair to infer that the administrative agencies lack initiatives to submit the cases to judicial offices for various reasons. Among the many reasons identified, for instance, the administrative agency did not know whether the case satisfies the criteria for transfer, the key evidence was lost, and the case had already been subjected to an administrative punishment of some forms. These cases ended up not being the subject of any criminal punishment.

\section{Discussion}

Consistent with the aforementioned issues, it is clear that there are still many problems in the process of the marine illegal fishing control in China. To find out the main reasons that caused these problems, face-to-face interviews were carried out with staff both from the administrative agencies and the justice departments. Meanwhile, the interview was also extended to some academics and experts specializing in illegal fishing control.

During the interviews, many staff from the judicial system indicated that the main reason for the abovementioned problems is the "poor job" of the administrative department, for example the insufficient and inactive cases transferring, the unreasonable evidence collection and fixation. They explained that the illegal actions that occur at sea are quite special, meaning they are hard to detect, so a large part of the case clues need to be delivered by the fishery administrative departments. Meanwhile, the conviction for marine illegal fishing also depends on the effective evidence collection and fixation by the administrative agencies at the first moments they found the violations, as most of the evidences in such cases cannot be fixed again in the later judicial investigation process (Gu 2014). 
Therefore, if the administrative departments do not perform well in the process of administrative law enforcement, it will probably hinder the conviction and sentence in the later judicial stage.

To the judicial officers' statements above, the staff from administrative departments held some different views. In the interview, they acknowledged that their jobs were the key links to the marine illegal fishing control; however, they insisted that "poor job" is an unfair judgment of them. They indicated that there were a large number of difficulties in the administrative enforcement at sea, which would cause them to do their job ineffectively and inefficiently occasionally. In this article, several main obstacles the administrative officers facing are summarized through the interview records collection and the literature reading.

Firstly, there are some inherent difficulties in the process of marine law enforcement because the illegal actions always happened in the vast sea, which would make the cases hard to detect.

Secondly, the illegal fishermen's violent resistance to the administrative agencies has been fierce in recent years. However, the power of the administrative department authorized by law is not sufficiently strengthened to control them. For instance, the administrative officers cannot use any weapon to curtail the illegal fishermen's violent actions and also cannot detain them on the spot. In this regard, administrative officers were usually eager to get support from the justice departments, who own compulsory enforcement power and advanced equipment. However, the support and cooperation from justice departments are not enough currently, which can be demonstrated by the judgment analysis above. In all the cases we collected, only 31 of them show there is cooperation between administrative departments and judicial departments, comprising only $5.07 \%$ of all cases.

Lastly, the lack of uniform and clear law enforcement standards is another obstacle. Currently, the relevant regulations (e.g., the case transferring criteria, the evidence fixing standard, the case transferring procedure) are principled and inadequately operable, which always confuses the administrative officers.

The conversation with the scholars was the last stage of our interview. This group of interviewees was treated a little bit different from another two groups, because we showed and explained the results of our previous interviews to judges and administrative officers first, for the purpose of making sure they could fully understand the other parties' opinions. Based on the information from our previous interviews and their own professional knowledge, we hope that the viewpoints put forward by the scholars could be more comprehensive and objective. In the interview, most of the scholars indicated that different departments stand in their own perspective to analyze the causes of the problems, most of which were reasonable to some extent. Excepting the reasons mentioned above, there also exists some other more fundamental ones, for example the imperfection of China's maritime law enforcement system; the lack of a coordinated and unified maritime law enforcement management departments; legislative deficiency and inadequate punishment.

\section{Conclusions and Suggestions}

Through the analysis above, it can be inferred that one of the lasting solutions that can be adopted to solve the problems is to strengthen the enforcement capacity of the fishery administrative agency. However, the essential nature of the administrative power is noncompulsory, and the problems cannot be settled only by their self-improvement. Meanwhile, to follow the excellent example of the United States Coast Guard, a comprehensive maritime law enforcement department with compulsory power should be built to make the marine legal enforcement effective and efficient. Moreover, the improvement of the relevant legislations is also a key point that cannot be equally ignored. However, the measures above are long-term processes and some immediate actions are highly warranted. Currently, it is urgent to build up some coordination and cooperation mechanism between the administrative department (which is known as "Oceanic and Fishery Department" in China) and the judicial departments (which is "Maritime Police Bureau" in China) to make sure that more suspect illegal fishing cases could be transferred to the criminal justice departments and more illegal fishermen could get the punishments they deserved. To this end, a rapid curtailment of the crimes involving illegal fishing of the aquatic products could be realized. Therefore, the following suggestions are provided: 


\subsection{To Build Up the Suspect-Case Transferring Mechanism}

A reasonable linking mechanism between the fishery administrative agency and the criminal justice departments on the criminal suspect cases transferring is critical to solve most of the currently existing problems mentioned above. Therefore, it is very important to clarify each department's responsibilities and to facilitate their communication and cooperation (Jin 2017). To realize this proposal, a specialized legal document should be jointly formulated with the cooperation of Oceanic and Fishery Department, Maritime Police Bureau and the People's Procuratorate. To this end, the following contents should be considered in this proposed multilateral legal document:

\subsubsection{The Suspect-Case Transferring Conditions should be Stipulated Clearly}

The Article 340 of the Criminal Law stipulates the criminal constitutional elements of the illegal fishing of the aquatic products, which are further extended by judicial interpretation issued by the Supreme People's Court [2016] No. 16 and [2016] No. 17. However, the existing stipulations cannot be directly used to judge what kind of administrative case is a "suspect criminal case", when and how these cases should be moved to the judicial department. The legislation blank caused the insufficient suspect-case transferring and limited the number of accountable cases in the end. Therefore, we suggested that the suspect-cases transferring criteria should be clarified in the proposed multilateral legal document, which should be unified, easily understandable and operable. Meanwhile, as the criminal investigation resources are finite, some restrictions of the case transferring also should be stipulated to avoid some unnecessary case transferring: (1) the procedures of administrative law enforcement should be legal; (2) there must be enough legal evidence to demonstrate the occurrence of a suspected marine fishery crime. If the cases transferred by the fishery administrative agency cannot satisfy the aforementioned standards, the criminal investigation department has the power to refuse and send the case back to the transferring department.

\subsubsection{The Suspect-Case Transferring Procedure should be Clarified}

As mentioned above, the exiting procedure for the suspect-case transferring was not specific and unified, which always caused a lot of contradiction. In this regard, we suggest that some necessary procedures should be clarified in the proposed legal document: (1) the suspect-case submission procedure for fishery administrative agency; (2) the suspect-case reception procedure for judicial investigate department; (3) the criteria and procedure for the criminal investigate department's final decisions, which include case acceptance, the request for supplementary materials, case rejection, case re-transferring, etc.; (4) complaint procedure for fishery administrative agency.

\subsubsection{The Requirements for the Transferred Cases should be Stipulated Clearly}

As mentioned above, cases of illegal fishing at sea are highly special since once the relevant evidence was collected and retrieved by the marine fishery administrative officers at the scene of the crime, it was unlikely to be redone in the later judicial investigation process. Therefore, the documents transferred by the marine fishery administrative agency are deemed as the critical evidence for conviction and sentencing. However, the criteria for administrative evidence collection and administrative document production are unclear, which always caused inconsistent evidence chain in the judicial process. Thus, it is suggested that the multilateral legal document should outline the specific requirements to guide the fishery administrative officers to collect and fix the key evidence in a legal and proper way, which include the identity information of the criminal suspect, the basic information of the illegal vessels, closed fishing period, closed fishing area, prohibited tools and methods, aquatic species and products fished, as well as the value and quantity of the fished products. 


\subsubsection{Evidence Examination and Conversion Mechanisms Should Be Established}

Obviously, it is impossible to avoid using the administrative materials in the judicial process. Therefore, the standards and procedure of the martial examination and verification should be built to make sure every administrative material adopted in judicial process is legal. Meanwhile, the standards of proof are quite different between the administrative law enforcement and the judicial law enforcement, and any evidence from the administrative process can be used in the judicial process only after judicial conversion. In this regard, we suggest that the rules governing evidence conversion should be clarified to be consistent with Article 52 of Criminal Procedure Law (2012), in which the following points should be observed:

(a) The physical evidence, documentary evidence, audio-visual materials and electronic data collected by the administrative agencies can be directly used in the judicial process if they were original and collected legally. Otherwise, they shall not act as criminal evidence unless they could be proved to be consistent with the original evidence.

(b) The test results, appraisal opinions and other similar documents offered by some independent professional institutions that were entrusted by the administrative agencies can directly serve as the evidence in the criminal proceedings if the social institutions own a legal qualification. When it is necessary, the criminal investigation departments can entrust other qualified institutes to offer the documents again.

(c) The inspection reports, examination records, inquest records and other similar documents produced by marine fishery administrative officers can be used in the judicial process if they were made legally. If the criminal investigation departments consider that it is necessary to re-collect, they can entrust other qualified institutes to offer the documents again.

(d) According to the Criminal Procedure Law, verbal evidence collected by the administrative agencies should be re-collected in the judicial investigation process. However, if it is impossible to collect this evidence again, it could be directly converted into criminal evidence with the support of other related legal evidence.

\subsection{To Improve the Procuratorate's Legal Supervision Mechanism}

The Chinese Constitution confers the People's Procuratorate a legal status of the judicial supervisory authority, which means that it supervises the administrative power and the other judicial power to make sure they work legally and effectively. However, it was found that currently, the People's Procuratorate does not pay much attention to supervise the suspect criminal marine illegal fishing cases transferring. In this regard, the following suggestions should be taken into consideration, and some of them can be stipulated in the proposed multilateral legal document.

\subsubsection{The Case Submission Supervision Mechanism Should Be Improved}

As analyzed above, fishery administrative agencies lack initiatives to submit the suspect cases to judicial offices for various reasons, which need to be supervised by the People's Procuratorate. Obviously, the People's Procuratorate cannot enforce its supervisory power only according to the Constitution stipulations, as they are always too principal. The explicit legislations concentrating on this issue are quite important; however this kind of legislation is still lacking in China. Currently, there are only some related government policies (e.g., "Notice on Transfer of Suspected Criminal Cases by the Administrative Law Enforcement Organs", "Opinions on Strengthening the Connection between Administrative Law Enforcement and the Criminal Justice departments"), the legal effect level of which is too low to support the Procuratorate's supervisory actions, which is one of the reasons for the problem of insufficient suspect case transferring in recent practice.

To address this problem, the Organic Law of the Procuratorates should be revised, in which the supervisory power of the Procuratorate over the criminal suspected cases transferring should be confirmed and some procedural details should be regulated. Regarding marine illegal fishing 
cases, some contents should be considered in the proposed multilateral legal document: (1) to clarify the duties of the fishery administrative agency to legally transfer every criminal suspect case to the criminal investigate department, and to send all the information to the Procuratorate in a timely manner. (2) To empower the Procuratorate to supervise the whole process of the criminal suspect cases submission. (3) To entitle the criminal investigate department to report and complain to the Procuratorate regarding the fishery administrative agency's improper actions. (4) To entitle the Procuratorate to access to the documents of the transferring cases, and to ask the administrative officials to explain its inquiries. (5) To entitle the Procuratorate to the give advices to administrative agency. (6) To entitle the Procuratorate to investigate and rectify any improper or illegal enforcement behaviors of the fishery administrative agency in the process of the criminal suspect cases submission. (7) To empower the Procuratorate to prosecute anyone who violate their own legal duties in the process of the criminal suspect cases submission.

\subsubsection{The Case-Filing Supervision Mechanism Should Be Optimized}

In practice, without enough reasonable reasons, some of the criminal investigation departments would refuse to accept the transferred illegal fishing cases or refuse to make a final decision on whether to accept the transferred case occasionally, which also needs to be supervised by the People's Procuratorate. In this regard, the following suggestions should be considered in the proposed multilateral legal document: (1) to clarify the duties of the criminal investigation department to accept any criminal suspect case legally transferred by an administrative agency, and to notify the administrative agency and the Procuratorate regarding the final decisions in a timely manner; (2) to entitle the fishery administration agency to report and complain to the Procuratorate regarding the criminal investigation department's improper actions; (3) to entitle the Procuratorate to access to the documents related to the decisions making, and to ask the criminal investigation officers to explain the inquiries; (4) to entitle the Procuratorate to give advice to the criminal investigation department; (5) to entitle the Procuratorate to investigate and rectify any improper or illegal enforcement behaviors of the criminal investigate officers; (6) to empower the Procuratorate to prosecute anyone who violates their own legal duties in the process of the criminal suspect cases transferring.

\subsection{To Strengthen the Supporting Systems}

The effective establishment of the linking mechanism between the administrative and criminal justice departments in their efforts to fight against illegal fishing crimes at sea is also dependent on the optimization of the relevant supporting mechanism. Therefore, the following systems should be considered in this proposed multilateral legal document:

\subsubsection{Joint Meeting Mechanism}

The fishery administrative agencies, the criminal investigation departments, and the People's Procuratorate should establish and optimize a long-term joint meeting mechanism. The liaisons of each department should be pointed to organize the joint meetings regularly. During the meeting, (1) the necessary information should be notified mutually; (2) any law enforcement problems could be consulted together, thereby countermeasures could be put forward effectively; (3) joint training could be carried out.

\subsubsection{Information Sharing Mechanism}

The fishery administrative agencies, the criminal investigation departments, and the People's Procuratorate should proactively build up the information-sharing platforms to share the necessary case information in a timely manner. All the departments involved in illegal fishing criminal cases handling should regularly report the case information in a timely manner and uploaded the necessary documents to the platforms at the same time. 


\subsubsection{Mutual Support Mechanism}

As the marine illegal fishing case were always complicated, sometimes it was very hard for the department to handle these cases by itself. Therefore, it is necessary to build up a mutual support mechanism to make sure each law enforcement department involved could seek professional help from other departments. The types of mutual support could include accepting consultation and giving suggestions, inquiry explanation, document offering, facilities offering, human resource supporting.

\subsubsection{Joint Law Enforcement Mechanism}

As mentioned above, the effect of administrative law enforcement is critical to the crime conviction and sentence of illegal fishing. However, the essential nature of the administrative power is noncompulsory-it could not conquer all the difficulties by its own. It is necessary to build up a joint law enforcement mechanism between the marine fishery administrative agency and the criminal investigation department to make sure the cases' clues could be found more easily, the evidence could be collected more sufficiently and properly, and the suspect cases could be judged more accurately and transferred more efficiently. In the joint investigation, the fishery administrative agency should solely focus on finding out the illegal acts of the offenders by collecting, extracting, monitoring, and fixing the evidence that the crime occurred in a timely manner. The criminal investigation department should examine the crime scene, focus on ascertaining the identity and position information of the responsible person, and take corresponding measures consistent with the law. These two departments should make comprehensive records through videos and photos of the crime scene.

Meanwhile, the marine fishery administrative department, the criminal justice department, and the People's Procuratorates are required to strengthen the joint supervision of the handling of major cases and jointly supervise the handling of major cases involving illegal fishing crimes.

Author Contributions: Writing-original draft preparation, P.H., L.F.; Writing-review and editing, P.C.; Supervision, C.Z. All authors have read and agreed to the published version of the manuscript.

Funding: This research received no external funding.

Conflicts of Interest: The authors declare no conflict of interest.

\section{References}

Chen, Guangzhong. 2015. Several Issues on Promoting the Reform of "Trail-Centric". Available online: https://www.chinacourt.org/article/detail/2015/01/id/1538341.shtml (accessed on 16 December 2019).

$\mathrm{Fu}$, Yuexin, Zhenke Zhang, and Zepei Ren. 2014. Status and countermeasures of illegal fishing of marine fishery resources in West Africa. Wsorld Regional Studies 4: 17-25.

$\mathrm{Gu}$, Yongzhong. 2014. Analysis on the evidence of administrative law enforcement "can be used as evidence in criminal proceedings". Journal of Law Application 3: 11-15.

Hao, Ruoxi. 2019. What affects judicial openness everywhere Rule. Law and the Society 3: 51.

Jin, Changwei. 2017. Study and Reconstruction of "Procedural Connection" Procedural Mechanism in Food Safety Cases. Journal of Law Application 9: 61-66.

Le Gallic, Bertrand, and Anthony Cox. 2006. An economic analysis of illegal, unreported and unregulated (IUU) fishing: Key drivers and possible solutions. Marine Policy 6: 689-95. [CrossRef]

Long, Yan. 2013. On Legislative Issues of Punishing Crimes of Destroying Environmental Resources-Comment on the Criminal Law Amendment (8) and related judicial interpretations. People's Tribune 23: 145-47.

Sun, Xiao-e. 2012. Empirical analysis of in-depth interview research methods. Journal of Xi'an Jiaotong University 32: 101-6.

Wang, Guanxiong. 2018. Discussion on Measures to Combat Illegal Fishing: EU Practices. Journal of Boundary and Ocean Studies 5: 22-36.

Wang, Jie, and Zhuo Chen. 2014. Research on the Integration of China's Maritime Law Enforcement Resources. China Soft Science 6: 30-38. 
Wang, Jiteng, Chengfei Ju, and Xin Jiang. 2017. Talking about the impact of US anti-aquatic product IUU and anti-fraud regulations on the export of aquatic products in China. Shandong Fisheries 34: 40.

Xinhua News. 2019. Rongcheng Weibo Fishery Co., Ltd.'s Illegal Fishing Case is the Largest Case of Corporatization and Collectivize Illegal Fishing in the Waters of Jiangsu Province in Recent 10 Years. Available online: https://js.qq.com/a/20180323/004638.htm (accessed on 11 December 2019).

Yue, Dongdong, and Lumin Wang. 2017. Problems Existing in the Supply Side of China's Marine Capture Fisheries and Reform Countermeasures. Journal of Agricultural Science and Technology 7: 23-32.

(C) 2020 by the authors. Licensee MDPI, Basel, Switzerland. This article is an open access article distributed under the terms and conditions of the Creative Commons Attribution (CC BY) license (http://creativecommons.org/licenses/by/4.0/). 